\title{
ANALISA POTENSI ENERGI ANGIN DI DAERAH ACEH BESAR SEBAGAI SUMBER LISTRIK UNTUK MENGGERAKKAN POMPA DI AREAL PERTANIAN
}

\author{
ANALYSIS OF WIND ENERGY POTENTIAL IN ACEH BESAR REGION \\ AS ELECTRICAL POWER TO DRIVE WATER PUMP IN AGRICULTURAL AREA
}

\author{
Teuku Zulfadli ${ }^{\left.{ }^{*}\right)}$ dan Andi Mulkan ${ }^{1}$ \\ ${ }^{1}$ Prodi Teknik Mesin, Universitas Iskandar Muda \\ Jl. Kampus Unida - Surien Banda Aceh 23234 \\ ${ }^{*}$ Email :zoel_m04@yahoo.co.id
}

Diterima: 05/08/2019; Disetujui: 30/08/2019

\begin{abstract}
ABSTRAK
Sistem drainase yang tidak baik merupakan salah satu permasalahan yang sering terjadi di beberapa daerah di kawasan Aceh besar yang merupakan areal pertanian. Berbagai macam usaha telah dilakukan oleh para petani diantaranya dengan mengalirkan air dari sumur dengan menggunakan pompa listrik. Keadaan ini membuat para petani harus mengeluarkan biaya tambahan untuk membuat instalasi listrik untuk menggerakkan pompa air dimana diperlukan kabel listrik yang panjang agar pompa dapat teraliri arus listrik. Untuk mengatasi permasalahan ini maka perlu dilakukan analisa potensi energi angin sebagai sumber energi listrik pada sistem pengairan di daerah pertanian Aceh Besar, terutama di desa Blang Krueng. Tujuan dari penelitian ini adalah untuk menganalisis sumber energi angin sebagai sumber listrik untuk menggerakkan pompa pada sistem drainase pertanian di Desa Blang Krueng Kabupaten Aceh Besar. Luas lahan pertanian yang menjadi analisis dalam penelitian ini adalah $\pm 0,5$ Hektar. Metode pengambilan data penelitian ini dilakukan dengan mengukur kecepatan angin dan analisa kebutuhan daya yang diperlukan untuk menggerakkan pompa. Dari hasil analisa diketahui bahwa kecepatan angin rata-rata pada Bulan April, Mei dan Juni 2019 berturut-turut adalah 2,93 m/s, $3,12 \mathrm{~m} / \mathrm{s}$ dan 2,91 m/s dengan rata-rata selama tiga bulan 2,98 m/s. Nilai kecepatan ini dapat dikatagorikan untuk penggunaan turbin angin kecepatan rendah (low speed wind turbine).
\end{abstract}

Kata Kunci: Energi Angin, Kecepatan Angin, Turbin Angin, Pompa Air, Sistem Drainase

\begin{abstract}
Not good drainage system is one of the problems that often occur in some areas in the area of Aceh large agricultural areas. Various kinds of efforts have been done by the farmers among them by supplying water from the well using an electric pump. This situation makes the farmers need to spend an additional fee to make an electrical installation to move the water pump where a long power cord is required for the pump to be supplied with electric current. To overcome this problem, it is necessary to analyze the potential of wind energy as electrical power in irrigation system in Aceh Besar agricultural area, especially in the village Blang Krung. The purpose of this research is to analyze the source of wind energy as a electrical power to drive water pumps on the agricultural drainage system in the village of Blang Krueng Kabupaten Aceh Besar. The area of agricultural land that became the analysis in this study was $\pm 0.5 \mathrm{Ha}$. The data retrieval method is conducted by measuring the wind speed and analysis of the power needs needed to drive the pump. From the results of the analysis is known that the average wind speed in April, May and June 2019 in a row is $2.93 \mathrm{~m} / \mathrm{s}, 3.12 \mathrm{~m} / \mathrm{s}$ and $2.91 \mathrm{~m} / \mathrm{s}$ with average for three month $2,98 \mathrm{~m} / \mathrm{s}$. The result can be categorized for low speed wind turbines.
\end{abstract}

Keywords: Wind energy, Wind Speed, Wind Turbine, Water pump, Drainage system

\section{Pendahuluan}

Aceh Besar merupakan daerah agraris yang mayoritas penduduknyabermata pencaharian sebagai petani. Hal ini dapat di lihat dari banyaknya 
lahankosong yang dapat dimanfaatkan sebagai lahan pertanian.Banyak petani yang memanfaat lahan kosong ini untuk menanam tanaman seperti padi, cabai, bayam, kangkung, sawi,tomat, dan tanaman lainnnya. Namun kesulitan yang di hadapi petani adalah pada saat musim tanam para petani harus bersusah payah memenuhi kebutuhan air pada tanaman mereka supaya hasil panennya tidak gagal. Bagi petani yang lahan pertanian berdekatan dengan pemukiman dapat memanfaatkan pompa air menggunakan listrik untuk mengalirkan air ke lahan-lahan pertanian. Namun bagi petani yang lahan pertanian jauh dari pemukiman harus bersusah payah mengangkat air dari sumur untuk menyiram tanaman mereka. Teknologi pembangkit listrik bayu merupakan salah satu teknologi yang dapat mengatasi hambatan tersebut di atas. Dalam penelitian ini, sumber energi yang digunakan adalah energi matahari dan energi angin. Energi listrik dari hasil konversi panas radiasi matahari dapat dimanfaatkan sebagai sumber energi listrik untuk menggerakkan pompa air. Energi angin akan dikonversikan melalui turbine angin untuk menghasilkan listrik. Dengan adanya kedua sumber ini diharapakan akan memenuhi kebutuhan energi listrik untuk menggerakkan pompa air sehingga sistem drainase akan lebih optimal.

Banyak penelitian yang telah dilakukan untuk meningkatkan pemanfaatan sumber energi terbarukan seperti perencanaan Pembangkit Listrik Tenaga Angin. Untuk itu pengkajian terus dilakukan secara mendalam untuk mendapatkan sistem pembangkit tenaga anginyang optimal dan tepat guna.

Penelitian potensi energi angin untuk menggerakan pompa telah dilakukan dalam jangka waktu 3 bulan dari April 2019 sampai dengan Juni 2019. Penelitian ini melibatkan mahasiswa tahun akhir Prodi Teknik Mesin Universitas Iskandar Muda sebagai bahan Tugas Akhir.

\section{Tinjauan Pustaka}

\subsection{Energi Angin}

Energi angin adalah energi yang terkandung pada massa udara yang bergerak. Energi angin berasal dari energi matahari. Pemanasan bumi oleh sinar matahari menyebabkan perbedaan massa jenis ( $\rho)$ udara. Perbedaan massa jenis ini menyebabkan perbedaan tekanan pada udara sehingga akan terjadi aliran fluida dan menghasilkan angin. Kondisi aliran angin dipengaruhi oleh medan atau permukaan bumi yang dilalui oleh aliran angin dan perbedaan temperatur permukaan bumi.karena digunakan sebagai bahan energi alternatif pengganti fossil dalam sistem pembangkit energi listrik. Turbin angin menerima energi kinetik yang dihasilkan oleh angin, dan melalui baling-baling yang terhubung dengan generator, energi angin tersebut dirubah menjadi energi listrik.

Kontribusi daya pembangkit listrik tenaga angin setiap saat tidak tetap, mengingat tenaga angin atau angin sangat bergantung dari kondisi alam. Angin adalah udara yang memiliki massa dan bergerak dengan kecepatan tertentu. akibat pergerakan ini, angin memiliki daya yang sebanding dengan massanya dan berbanding lurus dengan kuadrat kecepatannya. Secara ideal kecepatan angin yang menggerakkan kincir angin ada tiga, yaitu:

- kecepatan aliran angin masuk (Vi) atau kecepatan aliran angin menuju blade.

- kecepatan aliran angin saat mengenai blade (Va).

- Kecepatanaliran angin ketika meninggalkan blade (Ve).

Angin mempunyai tenaga yang sama besarnya dengan energi kinetik dari aliran angin tersebut, yaitu (Rinaldy): ${ }^{[3]}$

$$
P_{t o t}=m \cdot K E_{i}=m \cdot \frac{V_{i}^{2}}{2 \cdot g c}(\text { Watt })
$$

Dengan :

$\mathrm{P}_{\text {tot }} \quad=$ daya total angin (Watt)

$\mathrm{m} \quad=$ aliran massa angin $\mathrm{kg} / \mathrm{det}$

$V_{i} \quad=$ kecepatan angin masuk $\mathrm{m} / \mathrm{det}$

gc $\quad=$ faktor konversi $=1 \mathrm{~kg} \cdot \mathrm{m} / \mathrm{N} \cdot \operatorname{det}$

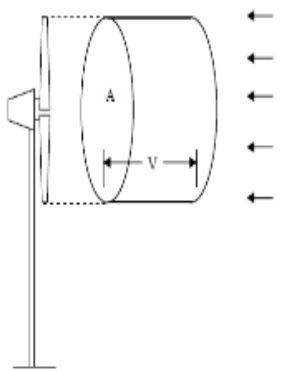

Gambar 2.1. Suatu bidang udara bergerak ke arah turbin angin

Sumber : Sathyajith Mathew (2006)

J.F Manwell, J.G Mc Gowan, (2002), daya angin berbanding lurus dengan kerapatan udara, dan kecepatan angin pangkat tiga yang alirannya tidak mengalami gangguan seperti kubik kecepatan angin, seperti diungkapkan dengan persamaan berikut: 
Analisa Potensi Energi Angin Di Daerah Aceh Besar Sebagai Pembangkit Listrik Untuk Menggerakkan Pompa Di Areal Pertanian

Teuku Zulfadli dan Andi Mulkan

$$
\mathrm{PW}=1 / 2 \mathrm{~A} . \rho \mathrm{V}^{3}\left(\mathrm{Watt} / \mathrm{m}^{2}\right)(2.2)
$$

Dimana:

$$
\begin{array}{ll}
\mathrm{Pw} & =\text { Daya dalam angin }\left(\mathrm{Watt} / \mathrm{m}^{2}\right) \\
\mathrm{A} & =\text { Luas area sapuan rotor SKEA }\left(\mathrm{m}^{2}\right) \\
\rho & =\text { Densitas udara }\left(1,225 \mathrm{~kg} / \mathrm{m}^{3}\right) \\
\mathrm{V} & =\operatorname{Kecepatan} \text { angin }(\mathrm{m} / \mathrm{s})
\end{array}
$$

Energi kinetik dari sebuah benda yang bergerak sebanding dengan massanya.Dengan demikian, energi kinetik dari angin tergantung pada kepadatan udara.Pada tekanan atmosfer normal dan temperatur $15^{\circ} \mathrm{C}$ kerapatan udara adalah 1,255 $\mathrm{kg} / \mathrm{m}^{3}$ meskipun nilai ini sedikit menurun dengan peningkatan kelembaban.

Koefisien daya dari turbin angin adalah pengukuran beberapa efisien turbin angin mengubah energi dalam angin menjadi listrik. Koefisien kekuatan pada kecepatan angin tertentu, adalah membagi listrik yang dihasilkan oleh energi total yang tersedia dalam angin pada kecepatan itu.

\subsection{Pengukuran potensi energi angin}

Data angin yang tersedia dalam rata-rata per jam atau rata-rata per hari selama kurun waktu satu bulanan dalam satu tahun akan diolah dengan menggunakan metoda-metoda statistik standar pengolahan data angin dan akan disajikan dalam beberapa buah bentuk grafik histogram berikut ${ }^{[8]}$ :

\section{a. Distribusi Waktu}

Plot data bulanan dengan rata-rata perhari dalam bentuk histogram memperlihatkan fluktuasi angin perharinya. Dari grafik ini kecepatan angin rata-rata perbulan dan pertahun dapat dihitung. Jika resolusi sampling pengambilan data rata-rata semakin kecil, misalkan 15 menit, informasi tambahan yang sangat berguna seperti kecepatan angin yang dirasakan dapat juga dikumpulkan.

Informasi lain yang didapat dari distribusi waktu adalah informasi mengenai perioda angin rendah di bawah suatu kecepatan angin rujukan. Untuk SKEA mekanikal informasi ini berguna dalam menentukan ukuran volume bak penampungan. Sedangkan untuk yang elektrikal informasi ini berguna untuk mengetahui perioda di mana turbin angin tidak beroperasi.

\section{b. Distribusi frekwensi}

Dalam kajian sumber daya angin, selain informasi mengenai distribusi kecepatan angin dalam kurun waktu tertentu, informasi mengenai jumlah jam perbulan atau pertahun untuk setiap nilai kecepatan angin diperlukan juga. Informasi ini disebut dengan distribusi frekwensi kecepatan angin.

Distribusi frekwensi kecepatan angin disajikan dalam bentuk histogram dengan ordinat jam dan aksis interval kecepatan angin. Histogram yang paling tinggi menunjukkan kecepatan angin yang paling sering terjadi tetapi bukan kecepatan angin rata-rata. Untuk daerah dengan kecepatan angin tidak terlalu bervariasi, bisa jadi kecepatan angin rata-rata adalah kecepatan angin yang paling sering terjadi. Tetapi di daerah dengan kecepatan angin yang sangat berfluktuatif pada umumnya kecepatan angin rata-rata lebih tinggi dibanding dengan kecepatan angin yang paling sering terjadi.

\section{c. Distribusi durasi dan distribusi dumulatif}

Penyajian data angin dalam bentuk distribusi durasi berguna untuk mengetahui jumlah jam di mana kincir/ turbin angin akan bekerja dan jumlah jam di mana kincir/ turbin angin akan menghasilkan daya yang berlebihan. Jika kurva yang didapat lebih horizontal maka daerah kecepatan angin tertentu akan lebih konstan. Sebaliknya semakin curam kurva distribusi durasi maka pola angin di berbagai daerah aliran semakin fluktuatif. Kebalikan dari distribusi durasi adalah distribusi kumulatif. Distribusi kumulatif akan memberikan informasi mengenai jumlah jam di mana kincir/ turbin angin tidak dapat beroperasi pada angin rendah atau berapa jam turbin angin beroperasi di bawah daya nominalnya.

Data angin sering juga disajikan dalam bentuk distribusi waktu untuk angin-angin berkecepatan rendah saja (Duration of Calms), misalkan di bawah 2, 3 atau $4 \mathrm{~m} / \mathrm{s}$. Sumbu Vertikal dari histogram ini adalah persentasi waktu total sedangkan sumbu horisontal disajikan dalam kelipatan logaritma pangkat 2n. Total Duration of Calms yang merupakan distribusi durasi untuk kecepatan-kecepatan angin rendah saja bermanfaat untuk melihat jumlah jam di mana turbin angin tidak dapat beroperasi.

\section{d. Distribusi weibull}

Data angin ini juga akan didekati dengan suatu fungsi kontinyu berupa distribusi Weibull untuk mendapatkan prediksi yang akurat mengenai keluaran turbin angin dan juga untuk mengetahui karakteristik pola angin.

Dengan melihat berbagai bentuk histogram penyajian data, dapat dicari informasi-informasi yang dibutuhkan mengenai karakteristik pola angin di suatu lokasi. Dengan mendekati data dengan menggunakan fungsi distribusi tertentu akan lebih berguna untuk meramalkan keluaran turbin angin 
Analisa Potensi Energi Angin Di Daerah Aceh Besar Sebagai Pembangkit Listrik Untuk Menggerakkan Pompa Di Areal Pertanian

Teuku Zulfadli dan Andi Mulkan

dengan lebih akurat dan juga untuk mengetahui berbagai informasi mengenai pola angin.

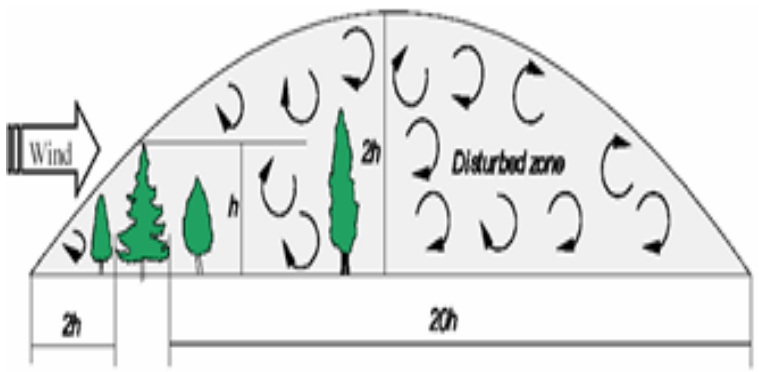

Gambar 2.2 Aliran berolak akibat rintangan ${ }^{[8]}$

\section{Metode Analisis}

\subsection{Waktu dan tempat penelitian}

Tempat Penelitian yaitu di desa Blang Krueng, Aceh Besar dengan luas $2 \mathrm{~km} 2$ dan jumlah penduduk 2110 orang,yang berjarak $20 \mathrm{Km}$ dari Universitas Iskandarmuda Banda Aceh, Provinsi NAD.

Data kecepatan angin diperoleh di desa blang krueng dengan ketinggian 5m dari permukaan tanah, data kecepatan angin di mulai dari pukul 08.00 WIB sampai 18.00 WIB menggunakan alat pengukur Anemometer Digital. Pengambilan data dilakukan selama 10 jam dalam satu hari selama 3 bulan, dari bulan April, Mei dan Juni tahun 2019. Hasil pengukuran tersebut akan dijadikan sebagai data primer.

\subsection{Prosedur penelitian}

1. Mengukur kecepatan angin dengan menggunakan Anemometer Digital

2. Data primer penelitian adalah data pengukuran dari bulan April,Mei, dan Juni 2019.

3. Menghitung potensi energi angin di Desa Blang Krueng Kecamatan Baitussalam, Aceh Besar.

\section{Hasil dan Pembahasan}

Data kecepatan angin selama tiga berturut mulai dari bulan April, Mei, dan Juni tahun 2019 dengan rincian sebagai berikut:

Tabel.4.1. Data Pengukuran Kecepatan Angin ratarata selama tiga bulan.

\begin{tabular}{|c|c|c|c|}
\hline Tanggal & Apr & Mei & Juni \\
\hline 1 & 1.96 & 2.06 & 3.04 \\
\hline 3 & 2.60 & 2.51 & 3.33 \\
\hline 5 & 2.95 & 3.21 & 3.02 \\
\hline
\end{tabular}

\begin{tabular}{|c|c|c|c|}
\hline 7 & 3.07 & 3.12 & 2.90 \\
\hline 9 & 2.76 & 3.81 & 2.98 \\
\hline 11 & 2.40 & 3.40 & 2.76 \\
\hline 13 & 3.09 & 3.07 & 3.05 \\
\hline 15 & 2.93 & 2.94 & 2.98 \\
\hline 17 & 2.93 & 3.97 & 2.47 \\
\hline 19 & 2.93 & 3.05 & 3.16 \\
\hline 21 & 3.15 & 3.18 & 2.72 \\
\hline 23 & 3.58 & 3.34 & 2.77 \\
\hline 25 & 3.03 & 3.14 & 2.68 \\
\hline 27 & 3.90 & 3.17 & 2.92 \\
\hline 29 & 2.70 & 2.81 & 2.89 \\
\hline Rata-rata & $\mathbf{2 . 9 3}$ & $\mathbf{3 . 1 2}$ & $\mathbf{2 . 9 1}$ \\
\hline
\end{tabular}

\section{Sumber: Data Penelitian}

\subsection{Hasil perhitungan potensi angin}

Pada kajian ini data diambil dari pengukuran potensi angin pada desa Blang Krueng Kecamatan Baitussalam Aceh Besar yang diukur pada ketinggian $5 \mathrm{~m}$ diatas permukan tanah selama 3 bulan, dari bulan April, Mei dan Bulan Juni 2019.

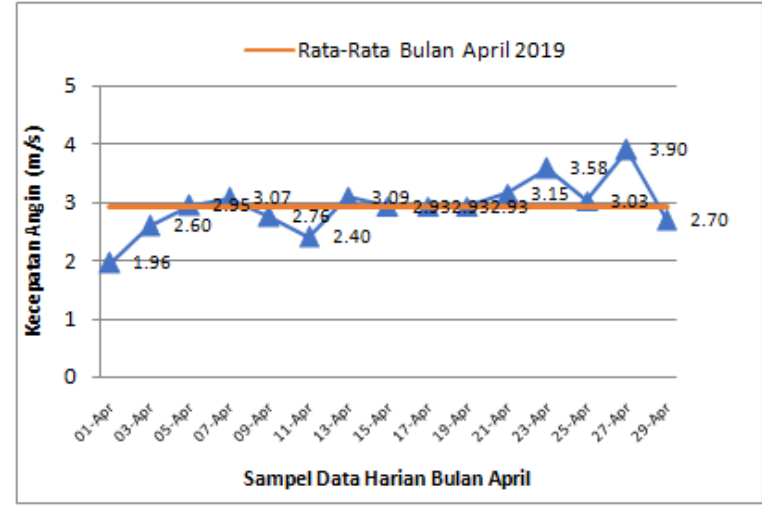

Gambar 4.1 Grafik hasil analisa data pengukuran kecepatan angin pada bulan April 2019

Berdasarkan grafik 4.1didapatkecepatan angin rata-rata pada bulan April yaitu $2.93 \mathrm{~m} / \mathrm{s}$. Dengan kecepatan angin tertinggi mencapai3.90 $\mathrm{m} / \mathrm{s}$ dan terendah rata - rata $1.96 \mathrm{~m} / \mathrm{s}$. 
Analisa Potensi Energi Angin Di Daerah Aceh Besar Sebagai Pembangkit Listrik Untuk Menggerakkan Pompa Di Areal Pertanian

Teuku Zulfadli dan Andi Mulkan

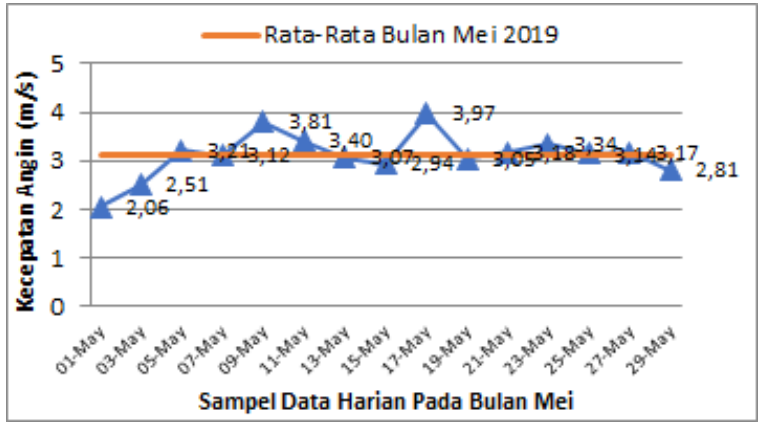

Gambar 4.2 Grafik hasil analisa data pengukuran kecepatan angin pada bulan Mei 2019

Berdasarkan grafik 4.2 didapatkecepatan angin rata-rata pada bulan Mei yaitu $3.12 \mathrm{~m} / \mathrm{s}$. Dengan kecepatan angin tertinggi mencapai3.97 $\mathrm{m} / \mathrm{s}$ dan terendah rata -rata $2.06 \mathrm{~m} / \mathrm{s}$.

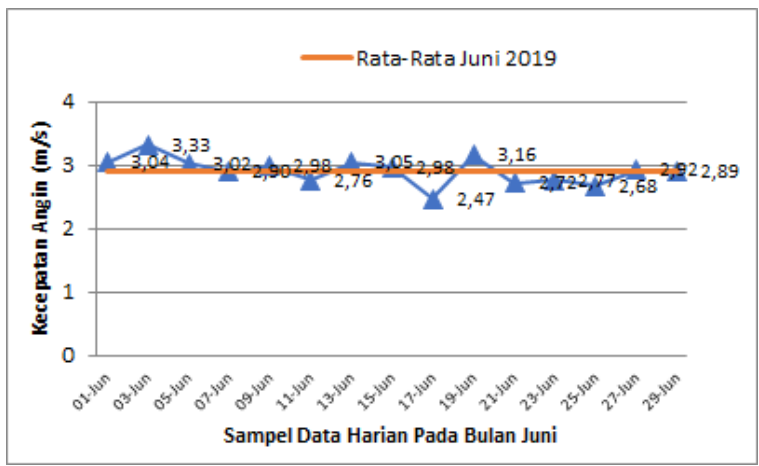

Gambar 4.3Grafik hasil analisa data pengukurankecepatan angin pada bulan Juni 2019

Berdasarkan grafik 4.3 didapat kecepatan angin rata-rata pada bulan Juni yaitu $2.91 \mathrm{~m} / \mathrm{s}$. Dengan kecepatan angin tertinggi mencapai3.33 $\mathrm{m} / \mathrm{s}$ dan terendah rata - rata $2.47 \mathrm{~m} / \mathrm{s}$.

\subsection{Kecepatan angin rata-rata bulanan untuk bulan April, Mei dan Juni Tahun 2019.}

Kecepatan angin rata-rata yang di peroleh pada bulan april yaitu $2.93 \mathrm{~m} / \mathrm{s}$, pada bulan mei 3.12 $\mathrm{m} / \mathrm{s}$ dan pada bulan juni $2.91 \mathrm{~m} / \mathrm{sselama} 10 \mathrm{jam}$.

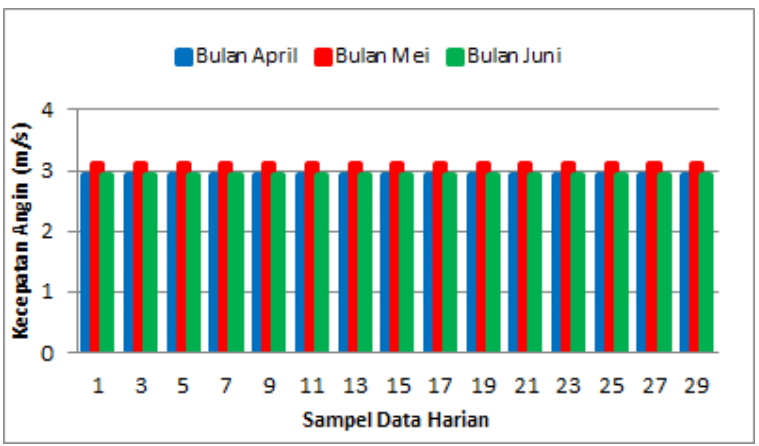

Jurnal Geuthèë: Penelitian Multidisiplin Vol. 02, No. 02, (Juni - Agustus, 2019), pp. 253-258.

Gambar 4.4 Grafik hasil analisa data rata-rata kecepatan angin perbulan pada bulan April Mei dan Juni tahun 2019

Berdasarkan grafik 4.4 didapat kecepatan angin rata-rata tertinggi pada bulan Mei yaitu 3.12 $\mathrm{m} / \mathrm{sdan}$ terendah rata -rata pada bulan Juni 2.91 $\mathrm{m} / \mathrm{s}$.

\subsection{Analisa Kecepatan Angin Bulanan pada bulan April, Mei dan Juni Tahun 2019.}

Data kecepatan angin diperoleh di desa Blang Krueng Kecamatan Baitussalam Aceh Besar dengan ketinggian $5 \mathrm{~m}$ dari permukaan tanah selama 3 bulan yakni dari bulan april hingga bulan juni tahun 2019. Hasil pengukuran tersebut akan dijadikan berupa data dan grafik besaran.

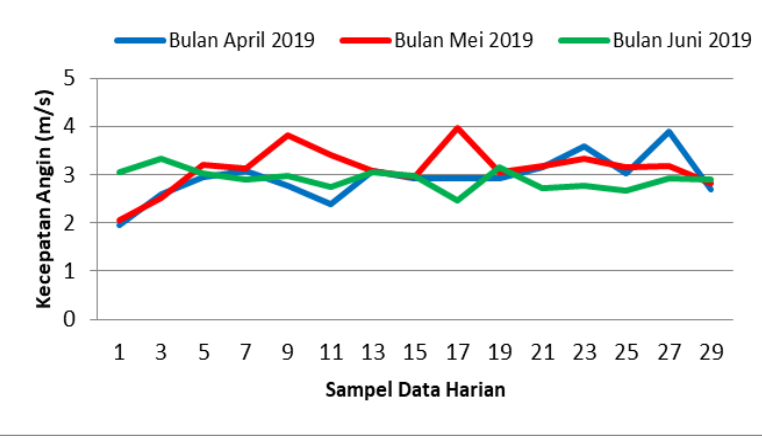

Gambar 4.5 Grafik hasil analisa data pengukuran rata-rata kecepatan angin selama tiga bulan April Mei dan Juni tahun 2019

\section{Kesimpulan}

Dari hasil dan pembahasan potensi energi angin sebagai pembangkit energi listrik pada sistem pengairan di daerah pertanian Aceh Besar dapat disimpulkan sebagai berikut:

1. Potensi energi angin di bulan April tahun 2019, Aceh Besar dalam kurun waktu satu bulan dengan rata-rata kecepatan angin sebesar yaitu $2.93 \mathrm{~m} / \mathrm{s}$. Dengan kecepatan angin tertinggi mencapai $3.90 \mathrm{~m} / \mathrm{s}$ dan terendah $1.96 \mathrm{~m} / \mathrm{s}$.

2. Potensi energi angin di bulan Mei tahun 2019, Aceh Besar dalam kurun waktu satu bulan dengan rata-rata kecepatan angin sebesar yaitu $3.12 \mathrm{~m} / \mathrm{s}$. Dengan kecepatan angin tertinggi mencapai $3.97 \mathrm{~m} / \mathrm{s}$ dan terendah $2.06 \mathrm{~m} / \mathrm{s}$.

3. Potensi energi angin di bulan Juni tahun 2019, Aceh Besar dalam kurun waktu satu bulan dengan rata-rata kecepatan angin sebesar yaitu

Jurnal Geuthèë: Penelitian Multidisiplin, Geuthèë Institute, Banda Aceh. 23111. E-ISSN: 2614-6096. Open access: http://www.journal.geutheeinstitute.com. 
$2.91 \mathrm{~m} / \mathrm{s}$. Dengan kecepatan angin tertinggi mencapai $3.33 \mathrm{~m} / \mathrm{s}$ dan terendah $2.47 \mathrm{~m} / \mathrm{s}$.

4. Kecepatan angin rata-rata dari ketiga bulan tersebut adalah $2,98 \mathrm{~m} / \mathrm{s}$. Nilai kecepatan angin ini dapat dikatagorikan untuk penggunaan turbin angin kecepatan rendah (low speed wind turbine) yang beroperasi pada kecepatan 1,7 $10 \mathrm{~m} / \mathrm{s}$ dan menggunakan 3 sudu.

\section{Daftar Pustaka}

1. Meliagrina (2014), Kajian Potensi Energi Bayu Sebagai Penggerak Pompa Pengairan Pertanian Daerah Saree Aceh Besar. Jurusan Mesin, Universitas Syiah Kuala.

2. Sathyajith Mathew, (2006). Wind Energy Fundamentals, Resource Analysis and Economics, Krips bv, Meppel Binding: Stürtz AG, Würzburg.

3. J. F. Manwell and J. G. McGowan, A. L. Rogers, (2009). WIND ENERGY EXPLAINED Theory Design and Application Second Edition. John Wiley \& Sons Ltd

4. Burton, T., Sharpe, D., Jenkins, N., Bossanyi, R., Wind Energy Handbook. England, Jhon Wiley \& Sons Ltd., 2001.

5. Y. Daryanto, (2007). Kajian Potensi Angin Untuk Pembangkit Listrik Tenaga Bayu, Balai PPTAGG- UPT-LAGG Yogyakarta

6. A.W. Culp, (1991). Principles of Energy Conversion, 2nd Edition (McGraw Hill International Edition, NewYork).

7. Henryson, M., Svensson, M. (2004). Renewable Power for the Swedish Antarctic Station Wasa. SWEDARP, Swedish Polar Research. Department of EnergyTechnology Stockholm, Sweden.

8. Sutrisna, Fendy, (2011), Pembangkit Listrik Tenaga Angin, Prinsip Kerja dan Proses Konversinya. Institut Teknologi Sepuluh Nopember (ITS) Surabaya

9. Kishore, Ravi Anant., Marin, Anthony. and Shashank, Priya. (2014). Efficient DirectDrive Small-Scale Low-Speed Wind Turbine. Research Article Energy Harvesting and Systems 1(1-2): 27-43 